\title{
Research Paper \\ The Motivation Analysis for Tourists Choice of Agritourism Destination: A Case Study of East Alamut, Iran
}

Hojat Varmazyari ${ }^{1}$, Alireza Rahimi ${ }^{2}$, Davoud Faghehi ${ }^{3},{ }^{*}$ Ali Asadi ${ }^{4}$

1. Assistant Professor, Department of Agricultural Management \& Development, Faculty of Agricultural Economic and Development, College of Agriculture \& Natural Resources, University of Tehran, Tehran, Iran.

2. PhD Student, Department of Agricultural Management \& Development, Faculty of Agricultural Economic and Development, College of Agriculture \& Natura Resources, University of Tehran, Tehran, Iran.

3. MSc., Department of Agricultural Management \& Development, Faculty of Agricultural Economic and Development, College of Agriculture \& Natural Resources, University of Tehran, Tehran, Iran.

4. Professor, Department of Agricultural Management \& Development, Faculty of Agricultural Economic and Development, College of Agriculture \& Natural Resources, University of Tehran, Tehran, Iran.

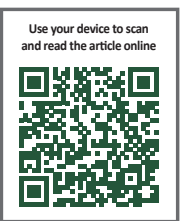

certation: Varmazyari, H., Rahimi, A., Faghehi, D., \& Asadi, A. (2017). [The Motivation Analysis for Tourists Choice of Agritourism Destination: A Case Study of East Alamut, Iran (Persian)]. Journal of Rural Research, 7(4), 644-657. http://dx.doi. org/10.21859/jjr-07044

: http://dx.doi.org/10.21859/jjr-07044

Received: 18 Aug. 2016 Accepted: 23 Nov. 2016

Keywords:

Destination choice, Agritourism, Motivation, Marketing, Alamut

\begin{abstract}
People's increasing demand for outdoor recreation, particularly those who live in metropolis and industrial cities, has created appropriate opportunity for income generation through agritourism by villagers. However, it may cause problems regarding the change of agricultural land use, should poor management practices be applied. One of the most important factors affecting income generation through agritourism is the recognition of tourism market and motivations of tourists. This study analyzed motives of tourists affecting the choice of agritourism destination. This study was a descriptive-analytical type of quantitative research conducted by a survey. The study population consisted of 18 years and older tourists visited the East Alamut region in summer. The sample size $(n=255)$ was determined based on tourists' motives and factor analysis perquisites. Convenience sampling method was employed because of lack of appropriate sampling frame. Respondents determined their highest priorities and motivations such as benefit from clean air, contact with nature, relaxation, and having a good time with family in a calm atmosphere. Also this study indicated that factors such as "being with family", "learning and spending less", and "self-actualization and change" were the most important factors in the choice of agritourism destination by tourists.
\end{abstract}

\section{Extended Abstract}

\section{Introduction}

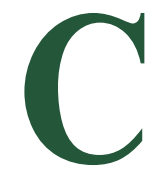

urrently Iranian small farms lack viable situations. Usually small villagers did not look at agriculture as a remunerative profession. Holistic and systemic look at various functions of a rural system, such as conservation, recreation activities, and non-use values and avoidance from reducing its functions to mere production, is one of the most important policies for complementary income generation and value adding in a farming system and improving its competitiveness. Establishing connection between agricultural sector and other sectors can create ample benefits for the communities, through developing backward and forward linkages. Tourism is one of the most important sectors that can contribute in

\section{* Corresponding Author:}

Ali Asadi, PhD

Address: Department of Agricultural Management \& Development, Faculty of Agricultural Economic and Development, College of Agriculture \& Natural Resources, University of Tehran, Mesbah Sq., Emamzade Hasan St., Tehran, Iran.

Tel: +98 (263) 2206825

E-mail: aasadi@ut.ac.ir 
fair and suitable agricultural marketing formation and reverse rural-urban outflow.

Regarding rapid growth of urbanization particularly in metropoles of Iran, dominance of small landholdings and existence of globally important agricultural heritages, sustainable agritourism is one of the most important strategies which could increase farmers' income and slow down agricultural land use change in Iran. In fact, the increasing demands of people, particularly in metropoles and industrial cities, for outdoor recreation has created appropriate opportunity for income generation through agritourism development. Of course it may cause problems regarding the change of agricultural land use, if good management practices do not be applied.

Recognition of tourism market and motivations of tourists strongly influences tourist attraction. Indeed understanding of customer motivation is a perquisite for achievement of tourism enterprises, especially agritourism enterprises (Goeldner \& Ritche, 2009). Motivations of tourists determine their decision about destination. Researchers should consider that the motivators of the individuals are different from each other (Castan, Moreno, García, \& Crego, 2003). Study of travel motivation is start point of psychological inquiries of tourist behavior. The best method of understanding favorite services of tourists and determining effective motivators is asking questions from themselves (Ranjbarian \& Zahedi, 2013). Nonetheless, motivations of Iranian tourists in the choice of agritourism destination have not studied yet. Thus this study has investigated these motivations.

\section{Methodology}

The necessary data for the study were collected through a survey conducted in Alamut County, Qazvin. After providing necessary explanations, respondents were asked to fill a 28-item questionnaire. In other words, the respondents were subject to 28 probable motivations which would influence agritourism destination choice.

Face-to-face interviews were conducted for completion of questionnaires, because citizens were not familiar with the term of agritourism. In other words, agritourism has not been publicly and formally initiated in the Iran. Respondents were provided with a brief introduction and explanation about the agritourism. After explaining the purpose of the study and agritourism, participants were asked to fill out the questionnaire on-site. On the basis of their importance in destination selection, respondents rated motivations from 1 to 10 . Some of these motivations were derived from the previous studies such as pleasure travel market survey and agritourism activities and others were provided in this study. These motivations were prioritized by $\mathrm{CV}$. Then principal component factor analysis and Varimax rotation were employed to determine the effective components in agritourism destination choice.

\section{Results}

According to the findings, the average age of the respondents was 35 years and their average family size was 3 persons. The visitors were planning to spend on average 22 hours in Alamut. Only 18\% of the visitors reported that they have resided in rural houses and pay money for it. Others have not paid any money for their residency, because they had resided in tents or in the open air and under trees shadow and houses of their relatives. On the other hand, about $74 \%$ of the respondents had gotten familiar with the rural areas of Alamut by face to face communication and word of mouth and only $4 \%$ of them had gotten familiar via the internet.

This study analyzed motives of tourists affecting the choice of agritourism destination. Respondents assigned the most priority to motivations such as benefit from clean air, contact with nature, relaxation, having a good time with family in calm atmosphere. Also this study indicated that factors, including "being with family," "learning and spending less cost," and "self-actualization and change" were the most important factors in the choice of agritourism destination by tourists.

\section{Discussion}

Iran is considered as a center of evolution of world agriculture and hosts several agricultural heritages. Unfeigned customs and traditions, traditional farming practices, indigenous knowledge, being as origin of many genetic resources, natural beauty and unique architecture have given competitive advantage for rural areas of Iran with respect to agritourism. Thus, Iran can open up new opportunities for agritourism development in the world. Nonetheless, agritourism has been not benefited from long and intensive research tradition, especially in Iran which is in turn necessitated more focused and organized research. The current study aims to fill this gap via motivation analysis for tourists' choice of agritourism destination.

\section{Conclusion}

The respondents of this study belonged to small and young families. It can be concluded that there is an appropriate opportunity for local community to formulate 
suitable plans and consequently job and income creation through tourism, because the visitors were planning to spend on average 22 hours in Alamut. The findings showed that tourism income derived from residency would decrease. On the other hand, there was dominance of conventional channels in marketing of agritourism destinations among the citizens. Finally this study presented some solutions to improve income generation via agritourism, as follows: 1) Emphasizing on small and young households; 2) Informing, educating, and trust-building among urban dwellers about residence at houses of rural people; 3) Providing better services for tourists to improve their royalty and use them as a part of marketing strategy; 4) Providing appropriate environment for visitors to spend a great time with their families in calm atmosphere; 5) Developing secure and convenient cites and facilities in rural areas for children enjoyment; 6) Catering local and safe food. 


\title{
تحليل انتَيزههاى تَردشَّران در انتخابمقصد تحرشكَرى كشاورزى (مطالعهموردى:بخش الموتشرقى)
}

\author{
حجت ورمزيارى'، عليرضا رحيمى'، داوود فاقعى" "على اسدى"
}

\begin{abstract}
ا - استاديار، كروه مديريت و توسعه كشاورزى، دانشكده اقتصاد و توسعه كشاورزى، يرديس كشاورزى و منابع طبيعى، دانشكاه تهران، تهران، ايران.

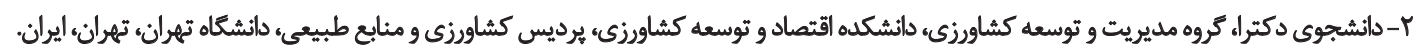

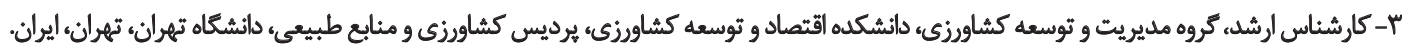

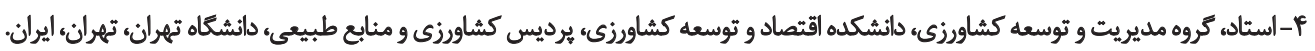

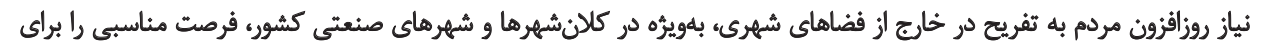

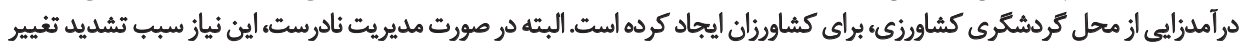

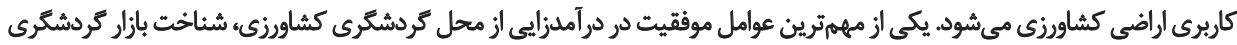

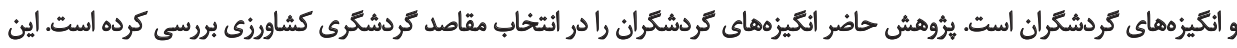

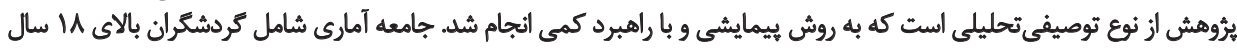

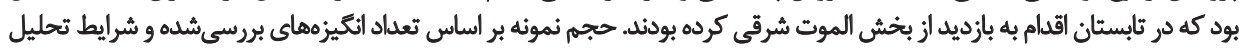

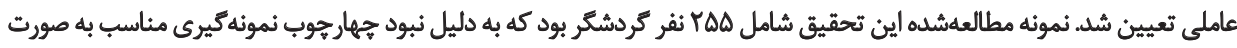

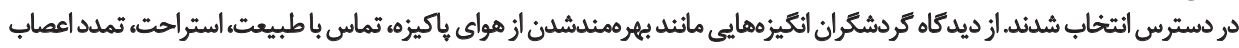

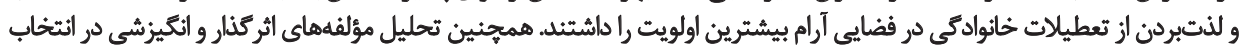

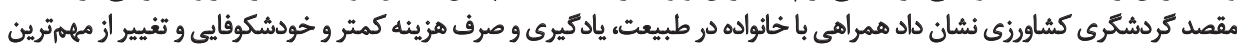

$$
\text { كاربرى كشاورزى اراضى است. }
$$

(

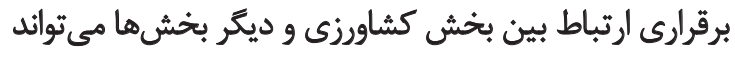

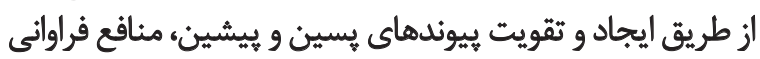

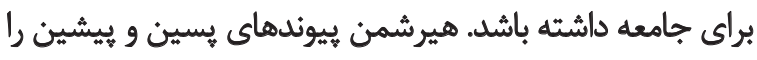

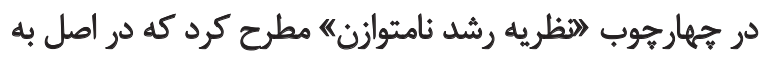

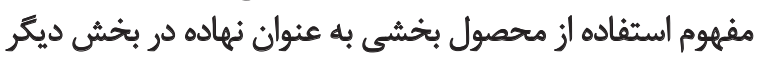

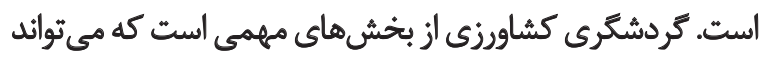

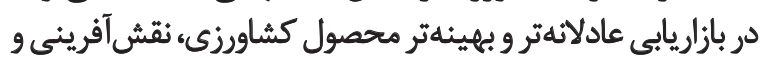

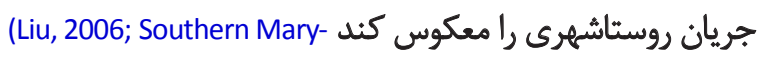

در حال حاضر واحدهاى كشاورزى كشور وضعيت وايدارى

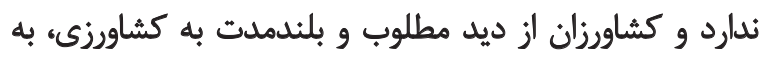

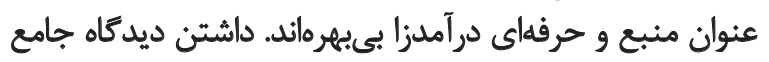

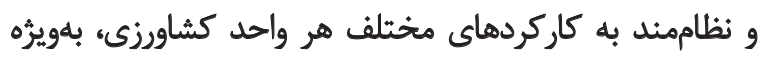

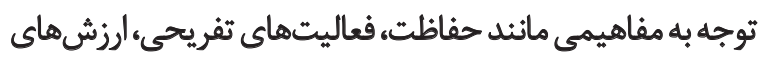

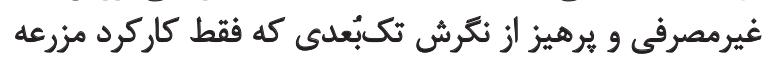

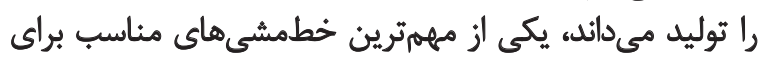

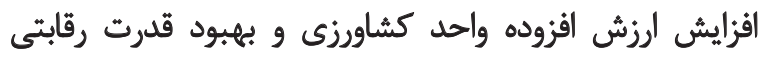




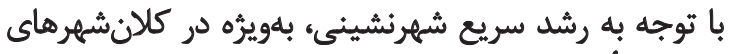

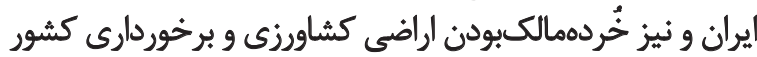

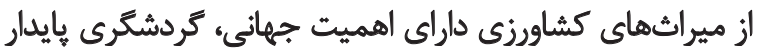

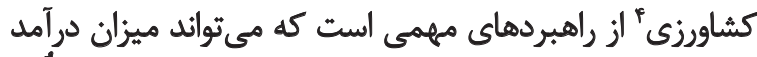

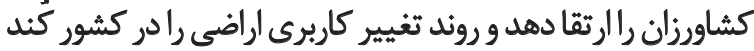

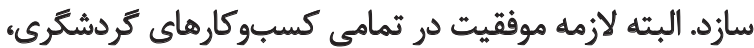

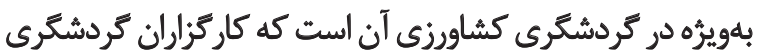
انكيزه مشترى را درك كنئد (Goeldner \& Ritche, 2009). انكيزه

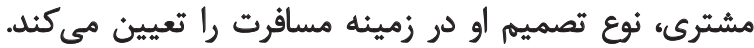

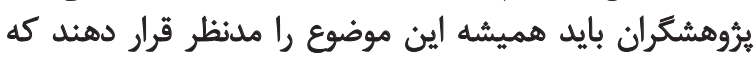

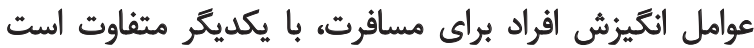

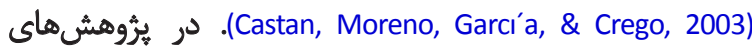

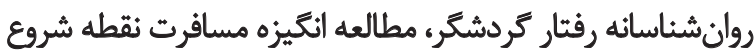

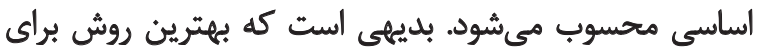

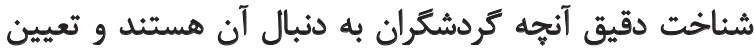

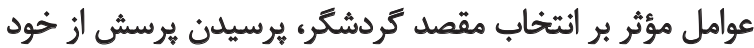
آنهاست (Ranjbarian \& Zahedi, 2013).

با وجود اين انتَيزهاى كردشكَران در انتخاب مقاصد

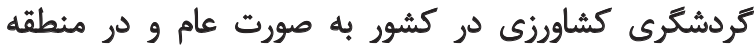

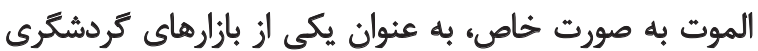

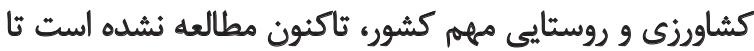

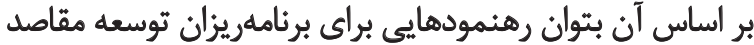

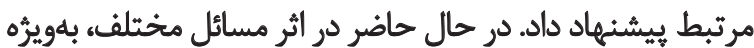

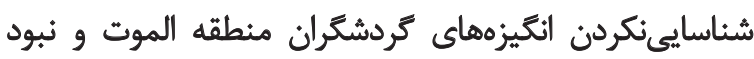

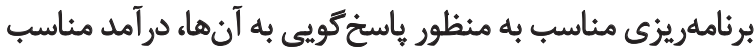

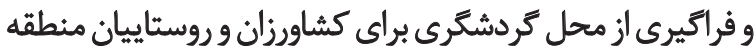

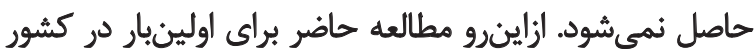

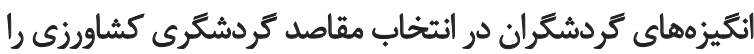
بروسي كرده است.

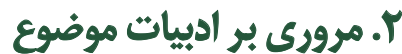

در حال حاضر انتيزش به فرامفهوم تبديل شده است و به مافي

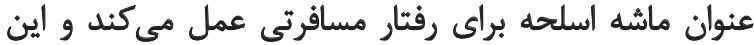

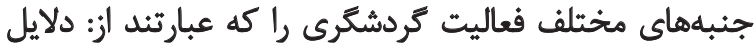

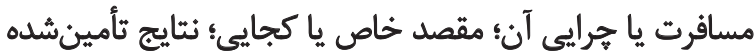
يا رضايتمندى كلى از سفر تعيين مى كند (Castan et al., 2003).

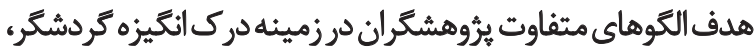

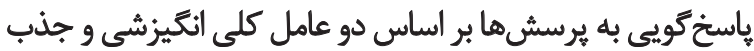

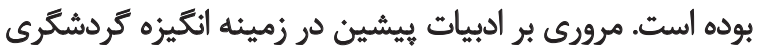

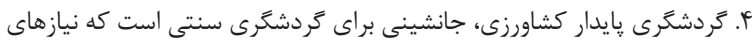

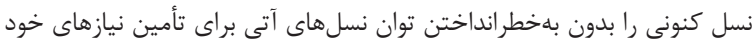

برآورده مىسازد (Mansury \& Hara، 2007). land Resources Conversation and Development Board, 2004)

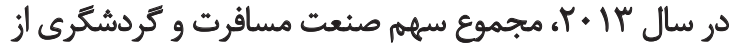

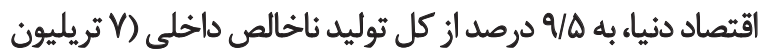

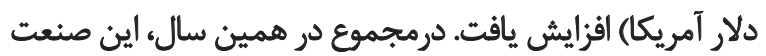

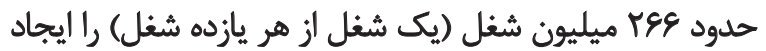

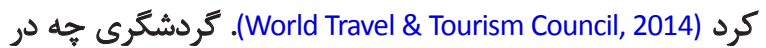

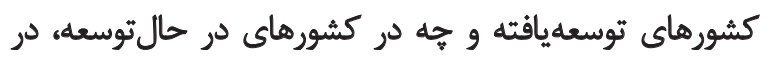

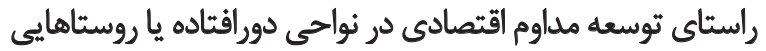

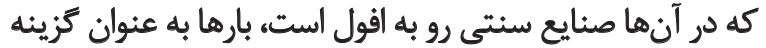
جايكزين مدنظر قرار كرفته است (Tianyu \& Yongguang, 2007).

كردشكرى كشاورزى از اشكال مهم تردشكَرى است كه مى تواند در مسير توسعه روستايى و كشاورزى نقش إئ ايفا كند.

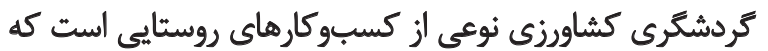

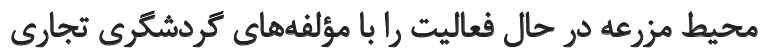

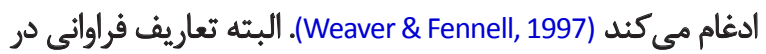

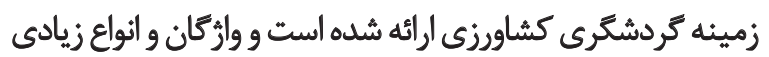

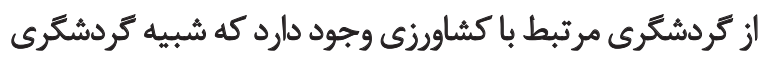
كشاورزى است. براى نمونه، معادل ارويائي والرّه

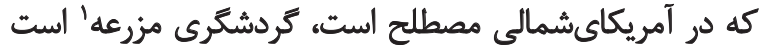

.(Busby \& Rendle, 2000; Getz \& Carlsen, 2000)

كردشكرى كشاورزى در آمريكا بيش از دو دها است كه به به

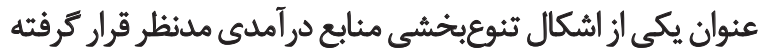

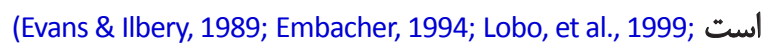
كنارش توسعة Soppermann, 1997; Pizam \& Poleka, 1980)

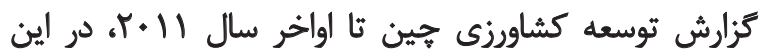

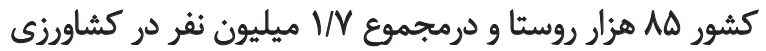

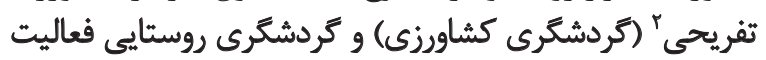

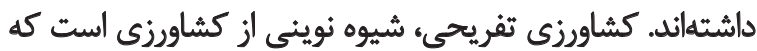

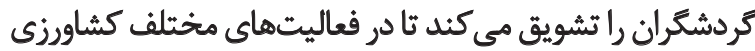

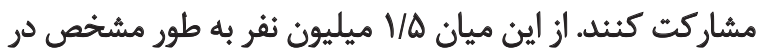
كردشكرى كشاورزى به فعاليت مشغول بودهاند.

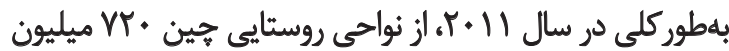

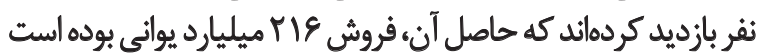

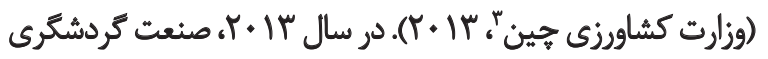

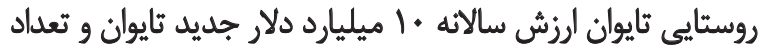

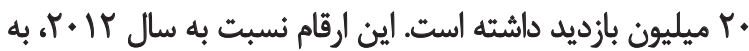

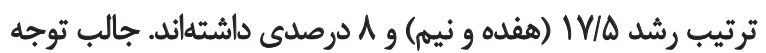

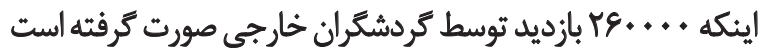
(شوراى كشاورزى تايوان (Council of Agriculture, 2014).

\section{Farm tourism}

2. Leisure agriculture

3. Ministry of Agriculture of People's Republic of China 


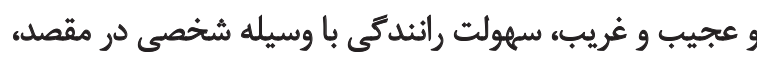

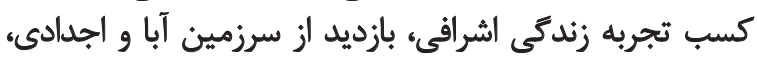

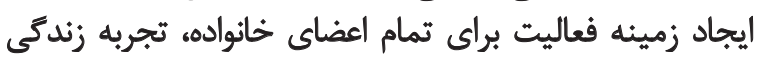

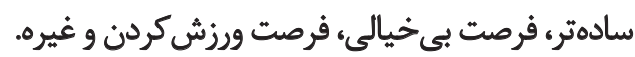
بررسيىها حاكى از آن است كه ثاكنون فقط نتايج يك مطالعه

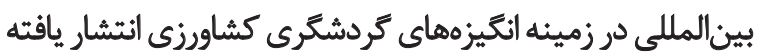

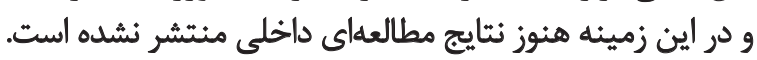

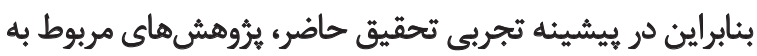

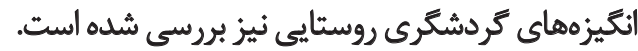
كميسيون حومه" (1994) در مطالعه انكَيزه كردشكران روستايي،

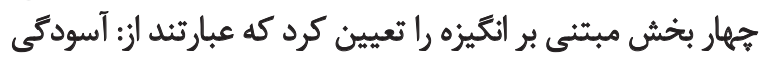

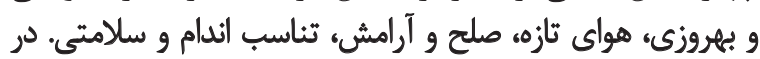

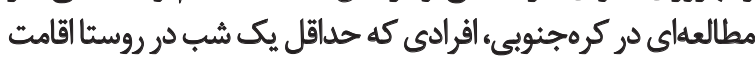

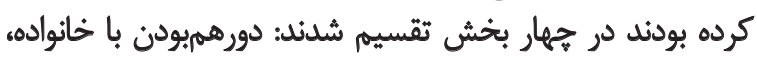

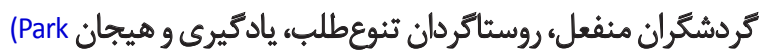

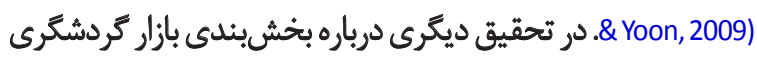

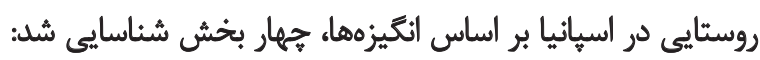

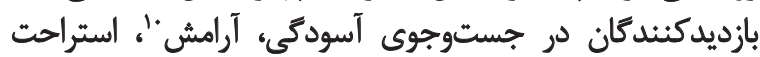

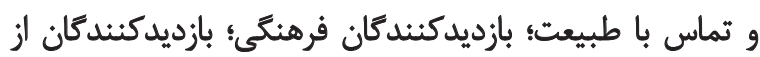

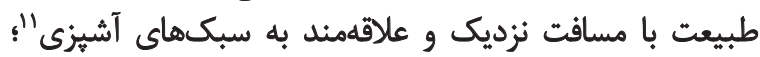
كردشكرى باز كشتي (Devesa, Laguna, \& Palacios, 2010).

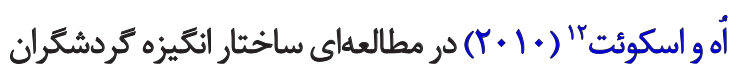

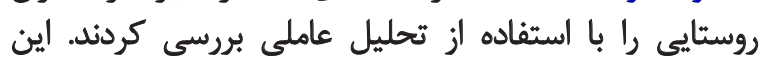

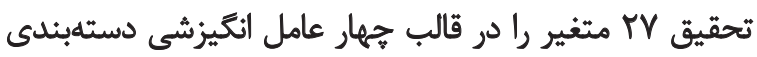

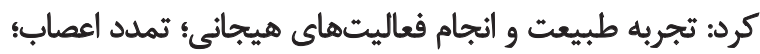

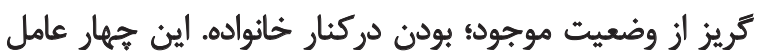

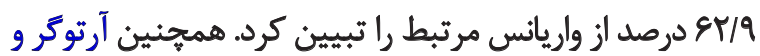

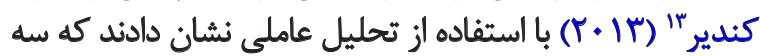

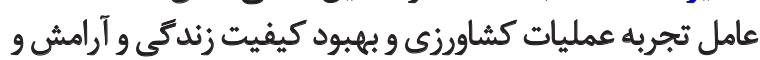
تمدد اعصاب، درمجموع \& \& درصد از انكيزه كردشئران كشاورزى

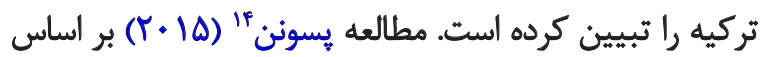

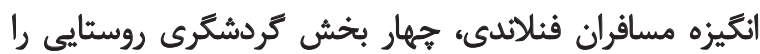

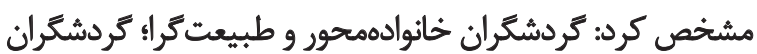

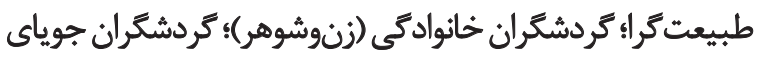

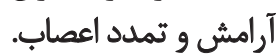

در ايران نيز فقط نتايج يك مطالعه درباره انكيزه كردشكران

9. Countryside Commission

10. Tranquillity

11. Proximity-gastronomic and nature visitor

12. Oh \& Schuett

13. Artuger \& Kendir

14. Pesonen

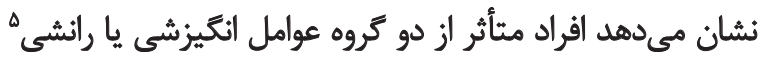

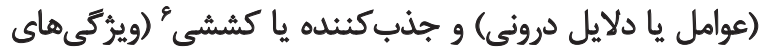

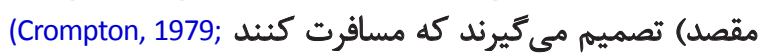
.Dann, 1977; 1981; Uysal \& Jurowski, 1994)

تموامل رانشى بيشتر به جنبه هاى داخلى يا احساسى، همجون

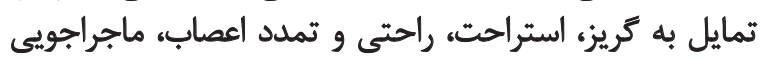

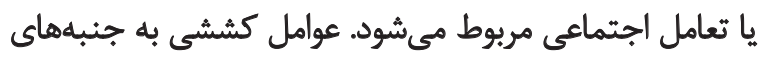

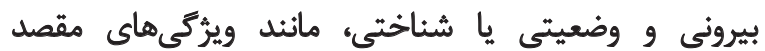

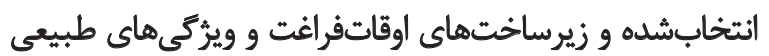

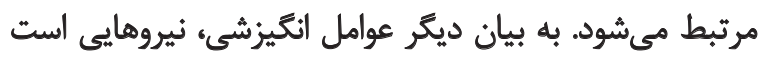

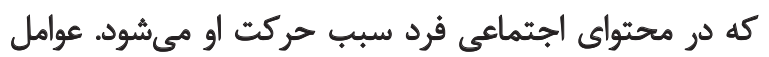

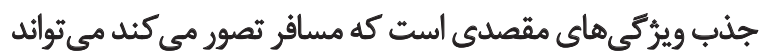

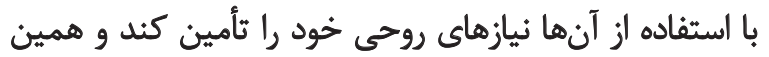

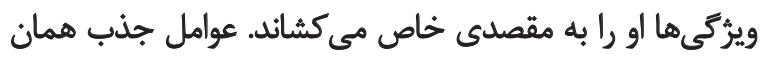

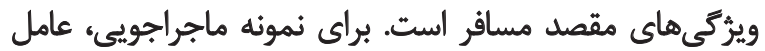

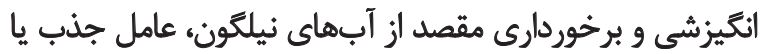

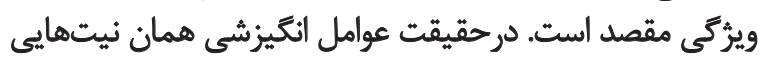

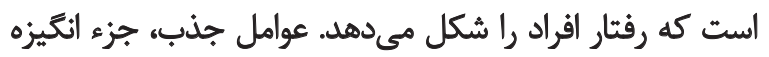

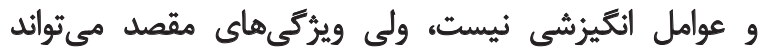
انكيزش هاى رانشى را تقويت كند (Yoon \& Uysal, 2005).

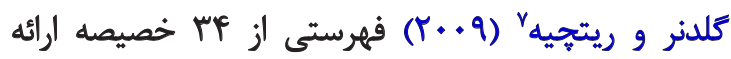

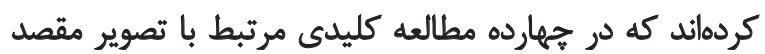

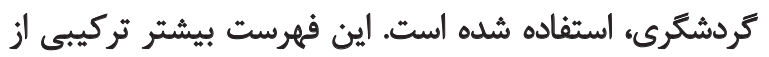

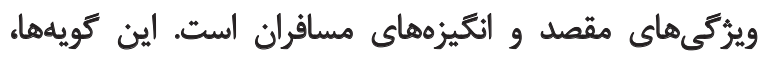

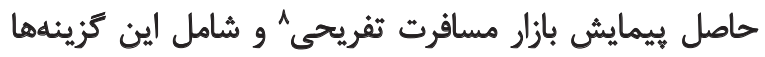

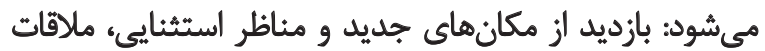

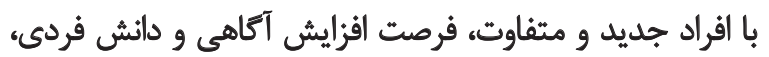

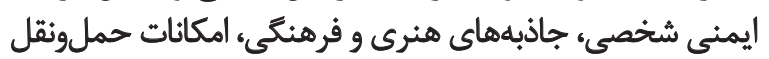

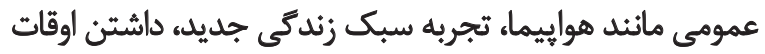

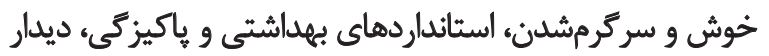

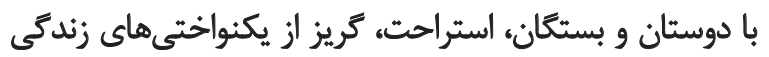

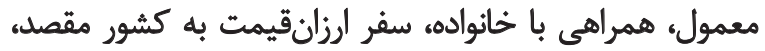

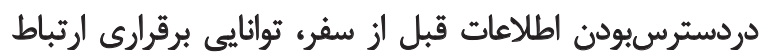

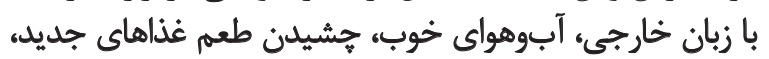

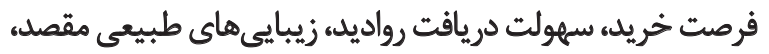

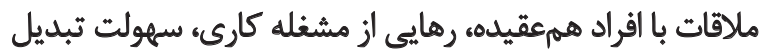

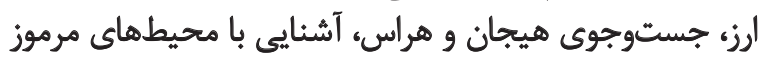

5. Push factors

6. Pull factors

7. Goeldner \& Ritche

^. ييمايش بازار مسافرت تفريحى (Pleasure Travel Market Survey)،

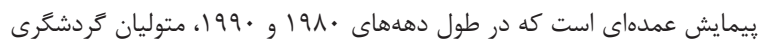
آمر يكا و كانادا آن را انجام دادهاند. 
متغير تعيين شد (Thompson, 2004). تُرساجها ( 19 (1)) حداقل

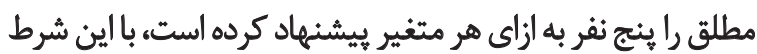

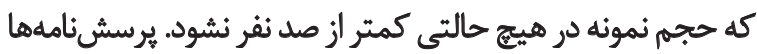

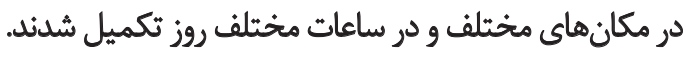
olwdultbodêt منطقه مطالعهشده، بخش الموت شرقى بود كهاز نظر جغرافيايي

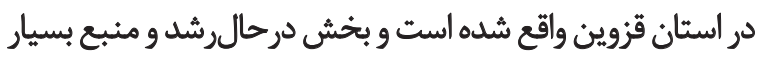

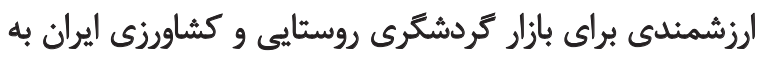

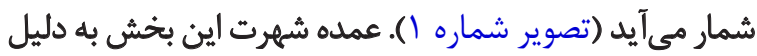

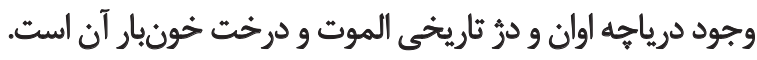

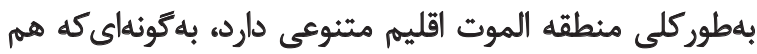

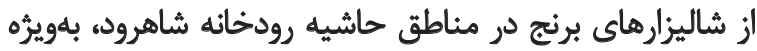

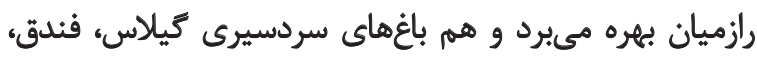

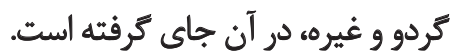

يكى از محصولهاى عمده كشاورزى الموت فندق است.

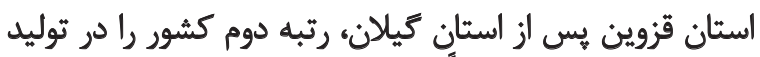

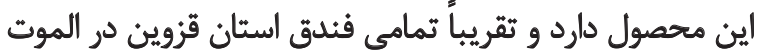

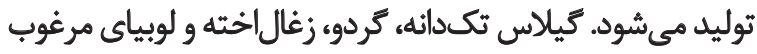

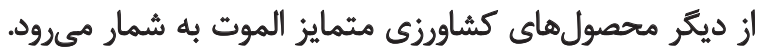

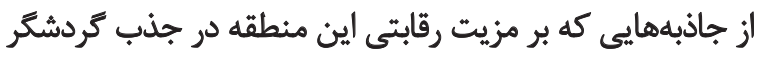

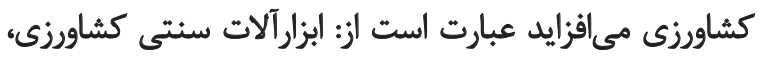

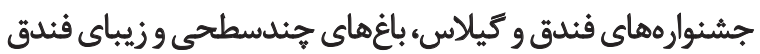

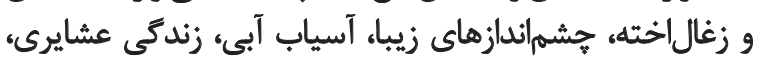

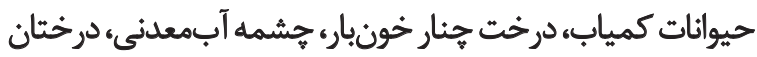

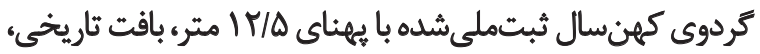

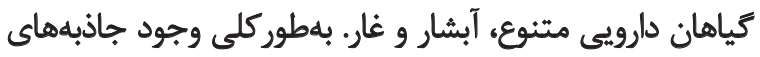

روستايى در ايتخاب مقاصد، آن هم درباره انتخاب مقاصد بيابانى

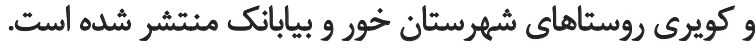

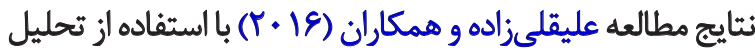

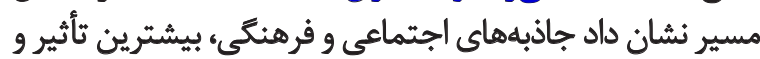

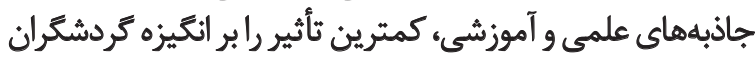

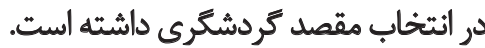

$$
\text { ب. ب. روش شناسى ثحقيق }
$$

روش اين بئوهش از نوع توصيفىتحليلى بود كه به روش إش

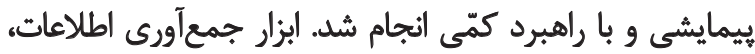

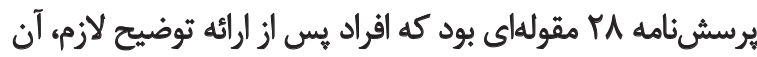

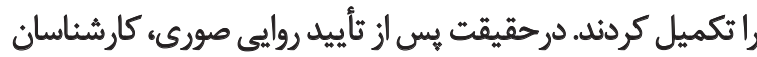

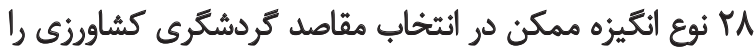

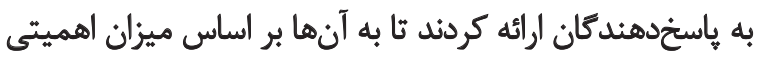

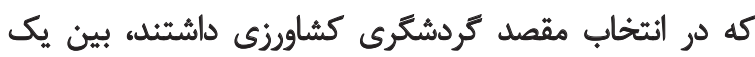

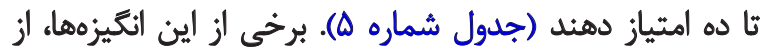

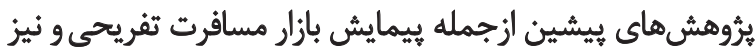

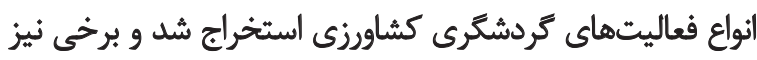

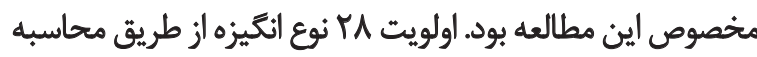

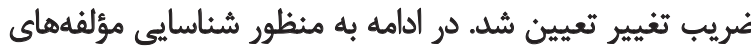

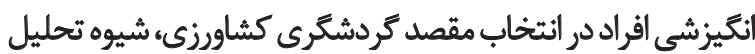

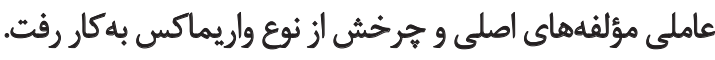

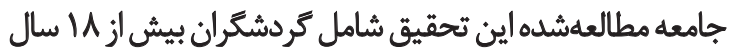

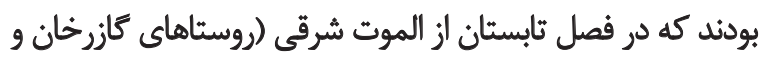

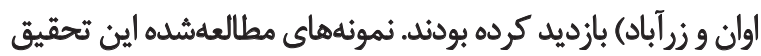

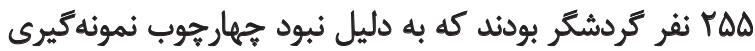

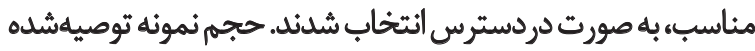

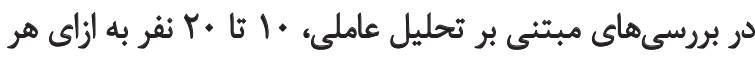

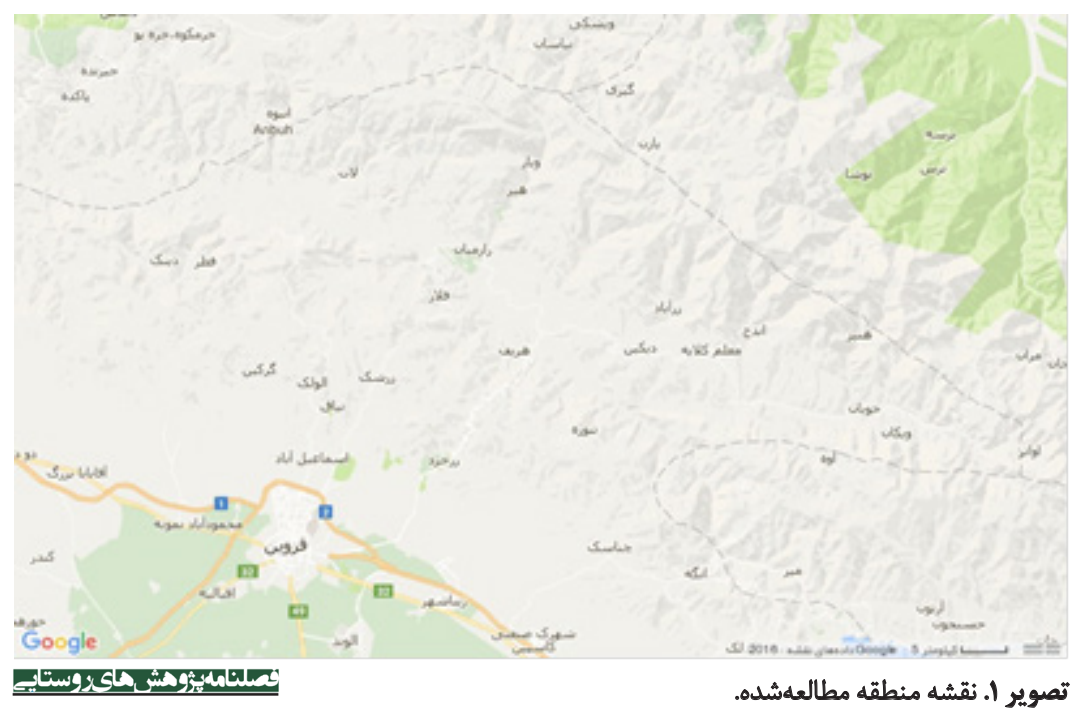




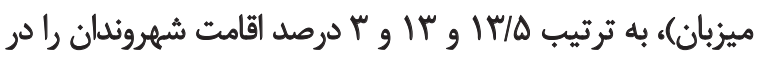

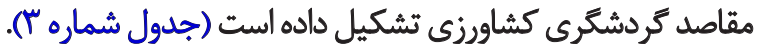

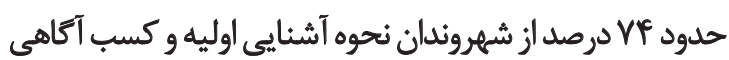

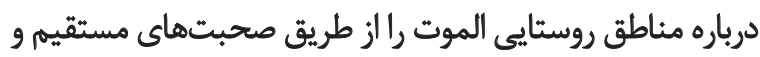

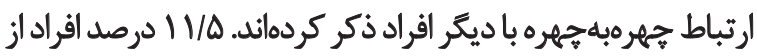

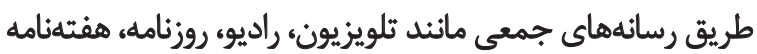

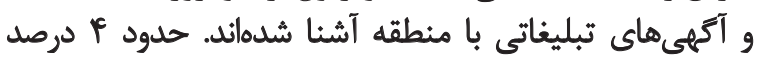

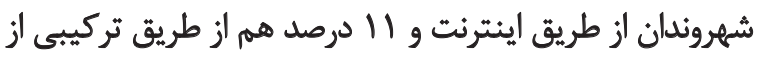

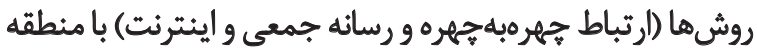

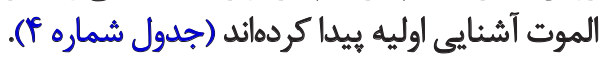

$$
\text { انغكيزههاى شهروثدان در كَردشكرى كشاورزى }
$$

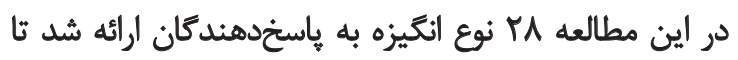

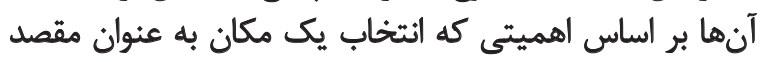

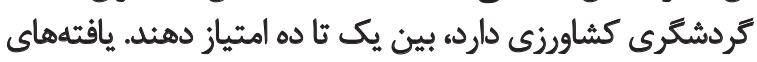

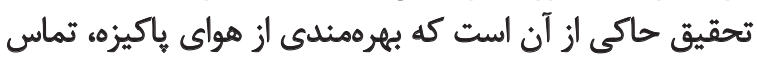

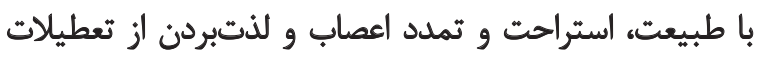

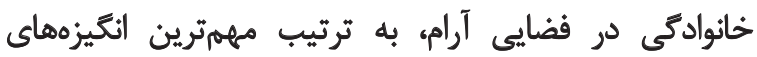

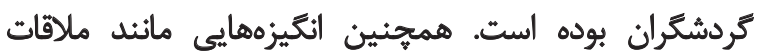

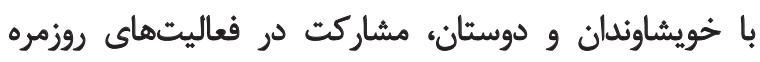
روستاييان، انجام فعاليت اقتصادى در روستا و تغيير در شرايط دري
كردشكُرى مخثلف در الموت، زمينه مناسبى براى ايجاد خوشه كردشكرى و همافزايى بين جاذبهافها فراهم كرده است.

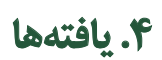

يافتههاى تحقيق حاكى از آن است كه افراد مطالعهشده در

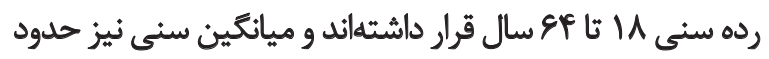

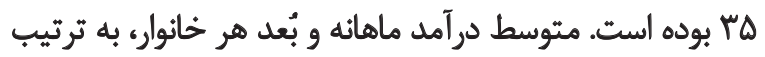

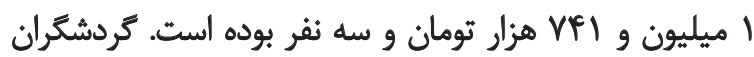

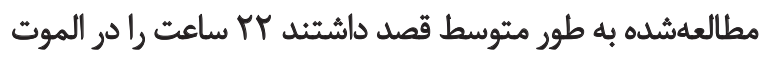
سيرى كنئ (جدول شماره ) ).

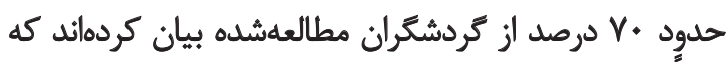

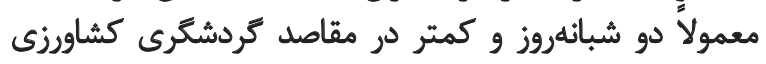

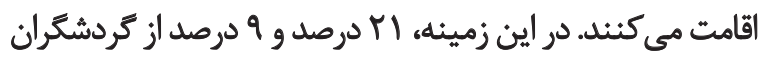

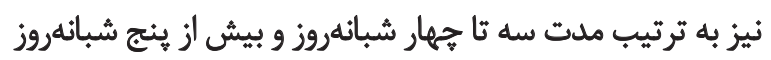
رالعلام كردهاند (جدول شماره ب)

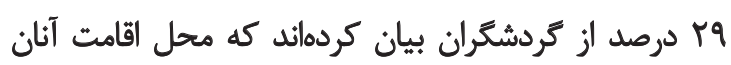

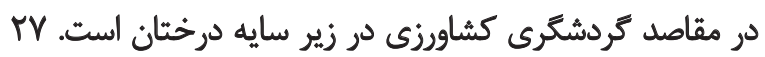

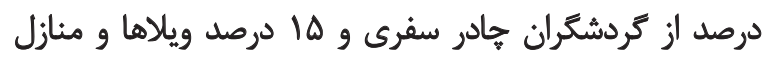

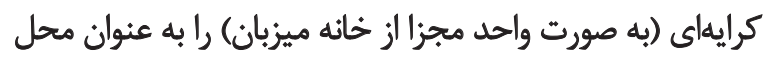

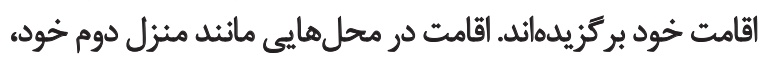

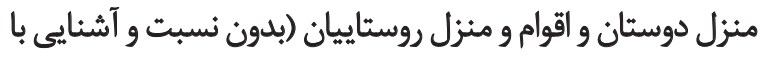

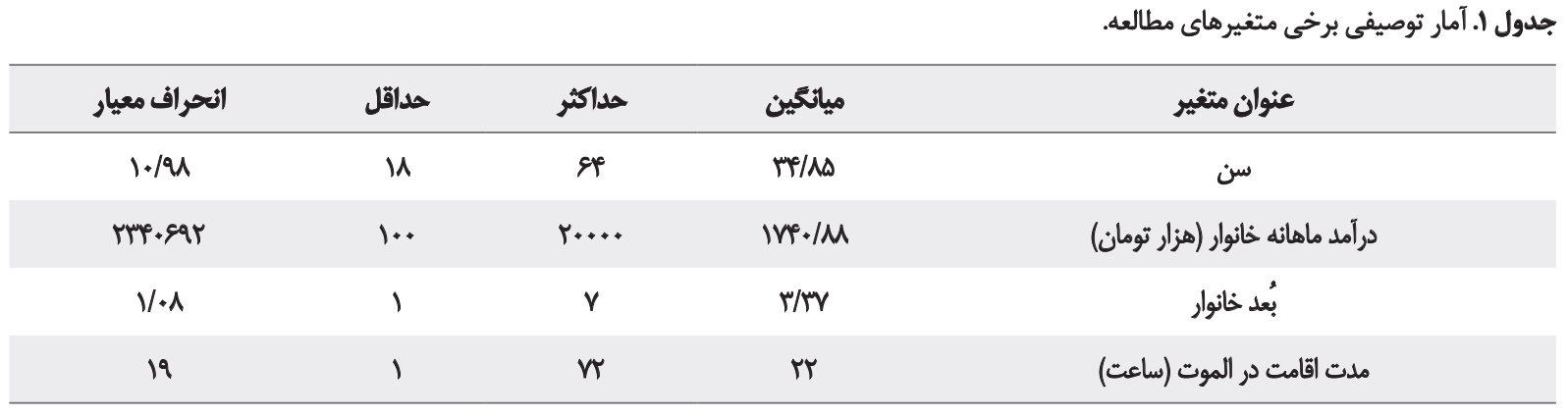

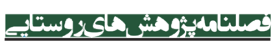

\begin{tabular}{|c|c|c|c|c|}
\hline درصد تجمعى & درصد معتبر & درصد & فراوانى & مدتزمان \\
\hline$r m / 1$ & $m / l$ & $M T / V$ & $\Delta M$ & كمثر از يك روز \\
\hline$s q / V$ & FE/g & $P \Delta / q$ & $11 \mathrm{~V}$ & يك تا دو روز \\
\hline $9 . / 1$ & 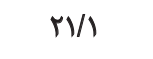 & $r \cdot / \Lambda$ & $\Delta r^{p}$ & سه تا جهار $2 و ز$ \\
\hline $1 .$. & $q / r$ & 9 & $m$ & ييشتر از يُنج روز \\
\hline- & - & $1 / 8$ & f & بلونياسخ \\
\hline- & $1 .+$ & $1 .$. & YAD & مجموع \\
\hline
\end{tabular}

جدول r. توزيع فراوانى افراد بر اساس مدتزمان سيرىشده در مقاصد كردشكرى كشاورزى. 
جدول ب. توزيع فراوانى افراد بر اساس مكان سكونت در مقصد كردشكّرى كشاورزى.

\begin{tabular}{|c|c|c|c|c|}
\hline درصد تجمعى & درصد معتبر & درصد & فراوانى & مكان سكونت در ثضاى روسيّا \\
\hline$r E N$ & $r E N$ & $r e / r$ & eV & هادر سفرى \\
\hline$\Delta \otimes / A$ & rVI & TNE & $n^{\prime \prime}$ & زير سايه مرخمتان \\
\hline $89 / \pi$ & $1 \% / \Delta$ & $1 \pi / \pi$ & $m$ & هئزل دوم خودم \\
\hline$A T / 1$ & $I T / N$ & $1 \% / \theta$ & Mr & منزل دوم دوستان و اقوام \\
\hline$\Lambda \Delta / \Gamma$ & $r / r$ & $m / 1$ & $\wedge$ & مثنل روستاييان \\
\hline $1 .$. & $I f / N$ & $1 F / \theta$ & $r$ & ويلا و منازل كرايهاى \\
\hline - & - & V/ & $p$ & بلونياسخ \\
\hline- & $1 .$. & $1 .$. & YAD & مجموع \\
\hline
\end{tabular}

تمست

جدول f. توزيع فراوائي افراد بر اساس نحوه آشنايي با الموت.

\begin{tabular}{|c|c|c|c|c|}
\hline تورل تجمعى & درود معتبر & مرصد & فراواتى & طريقه آشنايى با روستاهاى منطقه \\
\hline$n / 1 / \lambda$ & $n / 1 / \Lambda$ & $r / q$ & WE & ارتباط جهرهبلجهره \\
\hline $1 \Delta / T^{2}$ & $11 / \Delta$ & $11 / 4$ & rq & رسائهاي جمعى \\
\hline $1+*$ & $r$ & $r / q$ & 1. & اينثرنث \\
\hline $9 \cdot 10$ & $\Delta / r$ & $\Delta / 1$ & ir & رسانههاى جمعى و ارتباط جهرهبهجهره \\
\hline $94 / 1$ & $f / f$ & $r / \mu$ & 11 & اينترنت و ارثباط جهرهبلجهيره \\
\hline$\vartheta$ & $1 / r$ & $1 / r$ & r & ايتترنت و رسانههاى جمعى \\
\hline- & - & $1 / r$ & $r$ & بلدونياسخ \\
\hline- & $1 .$. & $1 .$. & YQD & مجموع \\
\hline
\end{tabular}

encing

بارتلت نيز در سطح 99 درصد معنى دار شد (جدول شماره ؟) كه حاكى از مناسب بارنيون متغير هاست (Kalantari, 2012).

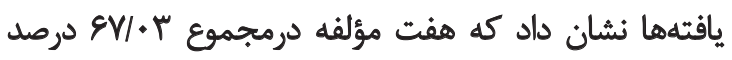

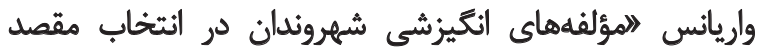

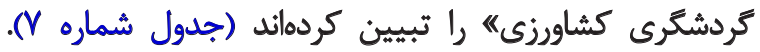

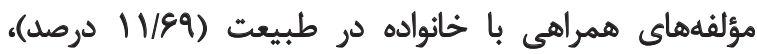

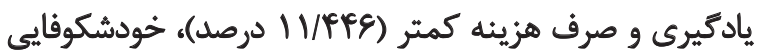
و تغيير (9/AVT درصد)، احساسات نوستالريك (

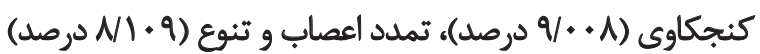

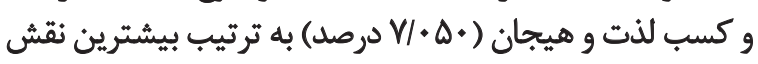

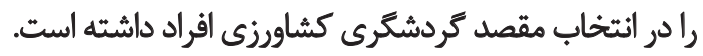

مؤلفه اول ينج متغير را شامل ميشود: الذتبردن از تعطيلات

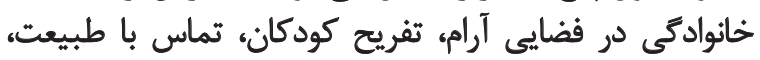

شخصى مائند مرك عضوى از خائواده، شكست در عشق، طلاق

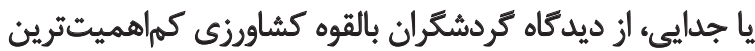
انكيزهها بوده است (جدول شماره ه).

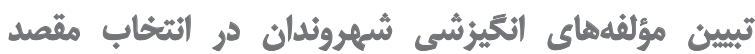

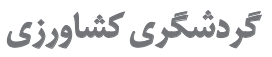

براى ثبيين مؤلفههاى انكيزشى شهروندان در انتخاب مقصد

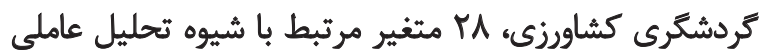

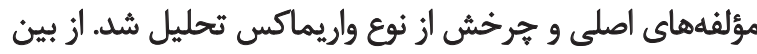

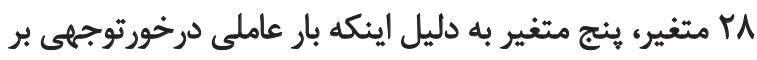

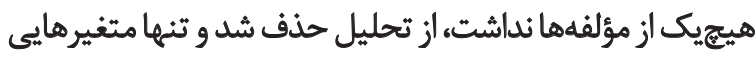

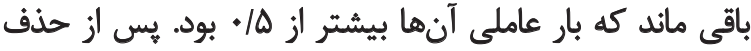

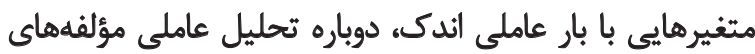

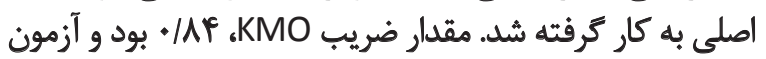


جدول هـ اولويتبندى ائكيزهاي مؤثر در انتخاب مقصد گردشكرى كشاورزى.

\begin{tabular}{|c|c|c|c|c|c|}
\hline ضريب تغييرات & انحراف معيار & مياتكين & تعداد & & كد \\
\hline . MTS & 1/990 & NNE & rof & بهرهمندشلن از هواي ياكيزه & 1 \\
\hline.$/ T A F$ & m/IVA & NAV & TAP & ارتباط با طبيعت & $r$ \\
\hline . MAT & $T / M A$ & NTI & TDF & استراحت و تملد اعصاب & r \\
\hline ( & there & NMT & TAP & لذتبردن از تعطيلات خانوادكى در فضاييى آرام & f \\
\hline . & $Y / \Delta \Delta A$ & $\mathrm{~V} / \mathrm{U}$ & TAP & خوشبودن با دوستان & $\Delta$ \\
\hline.$/ m \pi$ & r/AEF & $V / N$ & rAP & كريز از يكنواحتى زندكى & $\varepsilon$ \\
\hline . & r/EAY & V/৭Q & roP & كريز از فشارهاي زندكى ششهرى & $\checkmark$ \\
\hline$\cdot / F$ & r/৭AY & V/f & rof & كذرانلن الوقات شاد و ثخليه هيجانها & $\wedge$ \\
\hline.$|+8|$ & $\mu / 18$ & SIAs & raf & أشنايع و كشف مكان هاى جديد & 9 \\
\hline - /rat & T/ITF & $s / f \lambda$ & TAF & أشنايى با بناهاى جلديد & 1. \\
\hline$\cdot / \Delta+\Delta$ & $r / .94$ & $9 / 1$ & rof & خوردن غذاهاى محلى و سالهمتر & 11 \\
\hline $.10 \cdot \Delta$ & M/MTI & $8 / \Delta 9$ & rof & تثريح كودكان & ir \\
\hline .1019 & $r / r \cdot r$ & $s / \mathbb{V}$ & rof & هشاهده حيواثات وحشى & ir \\
\hline.$/ \Delta A F$ & $m / 1$ & $\Delta / 8$ & raf & آشثائي با زندكى روستايي اصيل & if \\
\hline . IOAY & $r / r \cdot r$ & $\Delta / \mathbb{R}^{\mu}$ & raP & ايجاد زمينه فعاليت براى تمام اعضاى خانواده & 10 \\
\hline.$/ 8$ & r/lar & $\Delta / T \Delta$ & raP & تُشان دادن تواناييىهاي شُخصى & if \\
\hline$\cdot 18 \cdot Y$ & m/IEY & $\Delta / T \Delta$ & rof & تجربه سبك زندكى روستايع & iv \\
\hline | & T/MEA & מ & raf & نشاندادن اعتمادبهنفس & M \\
\hline .1811 & 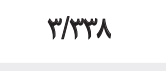 & $\Delta / t$ & TAF & كمهزينهبودن كذراندن تعطيلات در نواحى روستايى و كشاورزى & 19 \\
\hline $.194 Y$ & T/. & $P / N$ & TAF & آشنايى با كثاورىى & $r+$ \\
\hline . ISVD & T/gTr & $\Delta / / V$ & TAF & 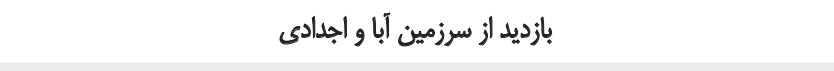 & $M$ \\
\hline . leve & $m(M T$ & P/gr & TAP & ملاقات با اقراد جلديل و متفاوت & M \\
\hline$\cdot N \cdot A$ & P/AFA & $\Delta / \cdot \odot$ & TAP & زئدهشن خاطرههاي دوران كودكى & Tr \\
\hline.$M M$ & ThAF & P/PA & rAP & شكوفايي خلاقيت & $r$ \\
\hline - MTr & r/PAY & p/vq & rAP & ملاقات با خويشاوندان و دوستان & ro \\
\hline - Ner & r/AYA & $r / N$ & TAP & مشاركت در فعاليتهاى روزمره روستاييان & re \\
\hline - & $w / W$ & $\mathrm{r} /{ }_{\mathrm{A}}$ & rAP & 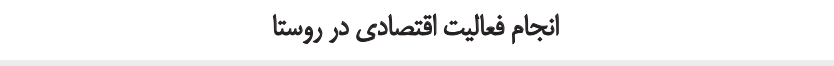 & rV \\
\hline IM9 & $m M \cdot p$ & $r / 1 / e q$ & rAf & تغيير در شرايط شخصى مائند مركى عضوى از خانواده، شكست در عشق، طلاق يا جلايع & YA \\
\hline
\end{tabular}

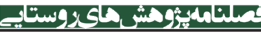


جدول \&. مقدار KMO و و آزمون بارتلت.

\begin{tabular}{|c|c|c|}
\hline سطح معنىدارى & بارتلث & KMO \\
\hline$+\ldots$ & MrTV/aY & . MAF \\
\hline
\end{tabular}

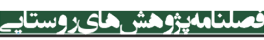

جدول V. تحليل مؤلفههاى اثركّار و انكيزشى شهروندان در انتخاب مقصد كردشكّى كشاورىى.

\begin{tabular}{|c|c|c|c|c|c|}
\hline تواريانس & واريائس از & مقدار & عاملى & متغيرها & ثام عامل \\
\hline $11 / 8 q$ & $11 / e q$ & $r / \& \wedge q$ & 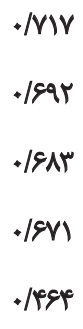 & 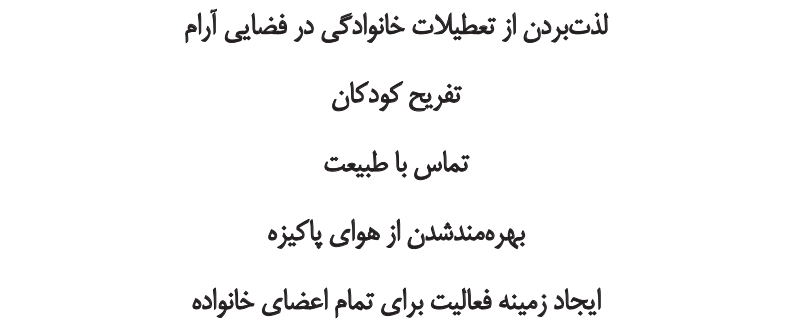 & هر هراهي با خانواده \\
\hline ritire & 11/fie & T/ETT & $\begin{array}{l}. / N T H \\
. / N+C \\
. / N+D \\
. / 019\end{array}$ & 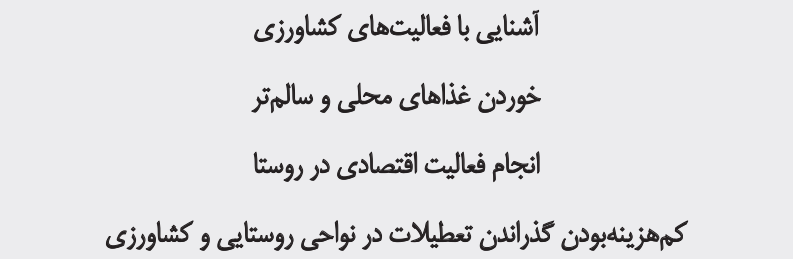 & يادكيرى و وصرف كمثر \\
\hline$H \Psi / * A$ & V/AVT & T/TY & $\begin{array}{l}\text {. NAT } \\
\text {. MAQ } \\
\text {. MPUI }\end{array}$ & 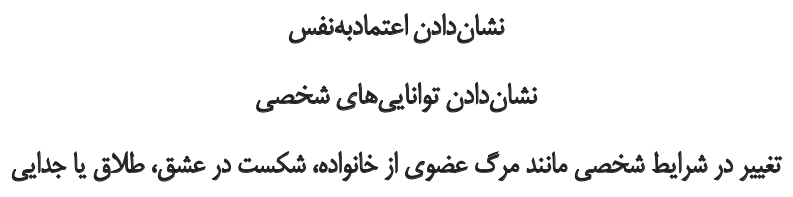 & خودشكوفايع و \\
\hline PY/NEI & QAAT & T/TES & 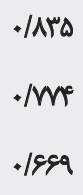 & 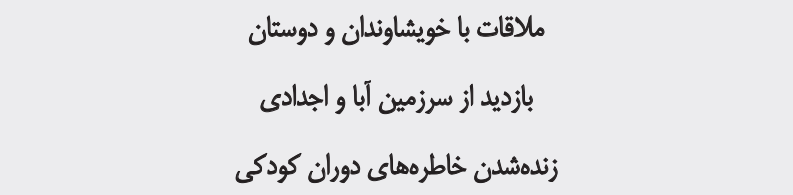 & نوستاسلثيك هائ \\
\hline$\Delta) / N=1$ & $q \cdot+1$ & $r / \cdot V$ & $\begin{array}{l}. / 299 \\
. / 1094 \\
. / 094\end{array}$ & 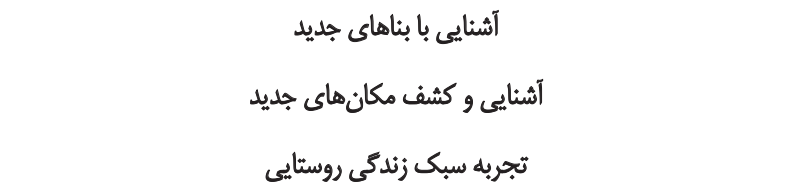 & كنجكاوى \\
\hline$\Delta q / 9 W$ & $N 1 \cdot q$ & $V / N \& \Delta$ & $\begin{array}{l}\cdot / 1+9 \\
. / M W \\
. / \Delta N T\end{array}$ & 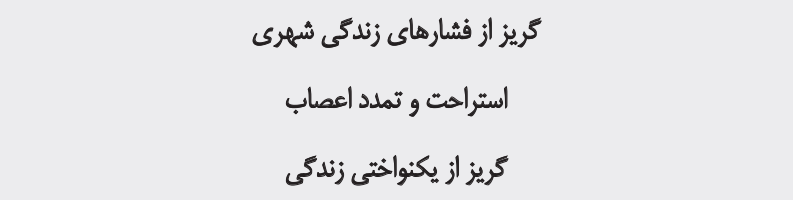 & تمدد اعصاب و \\
\hline ENl.TV & $V / 0$ & VEYT & $\begin{array}{l}\cdot|A| \\
\cdot \mid 1 \cdot 9\end{array}$ & 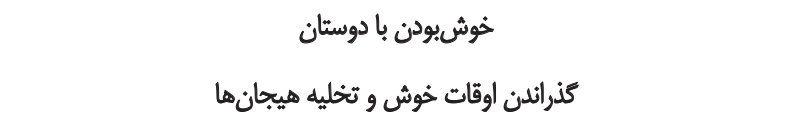 & كسب لذت و هيجان \\
\hline
\end{tabular}

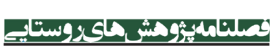


درآمدزايى خدمات محيطزيستى براى كشاورز و درنتيجه بهببود

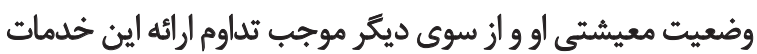

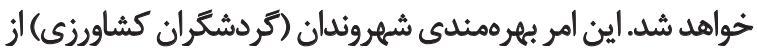

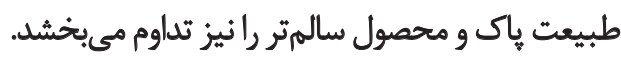

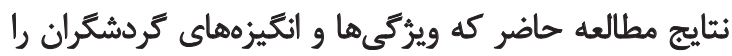

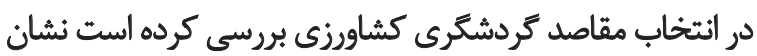

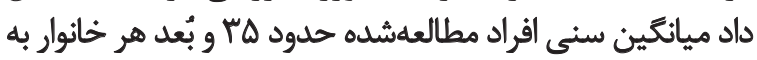

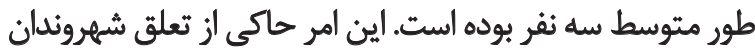

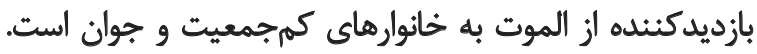

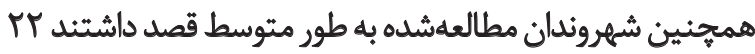

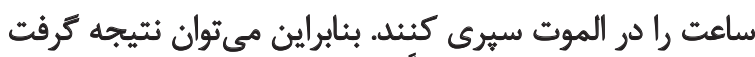

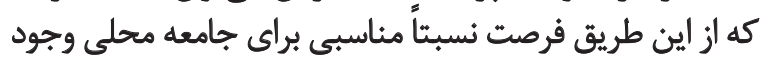

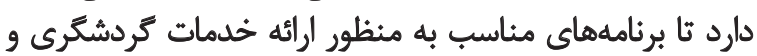

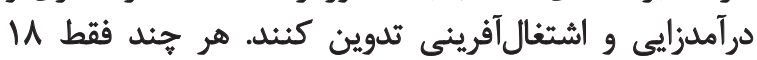

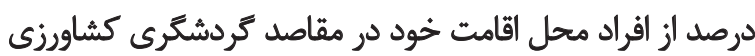

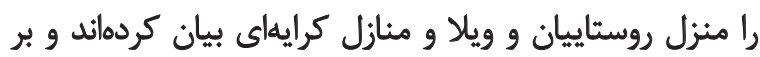

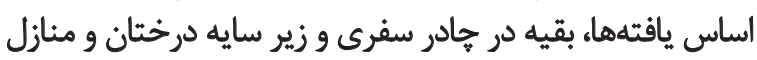

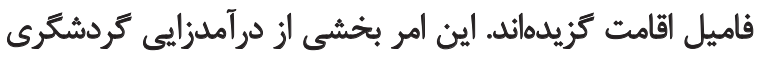

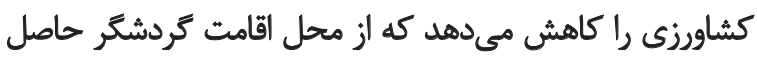

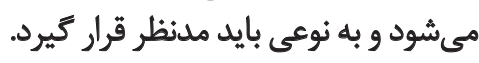

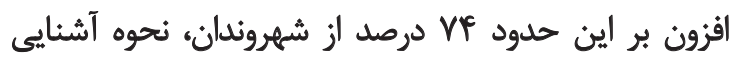

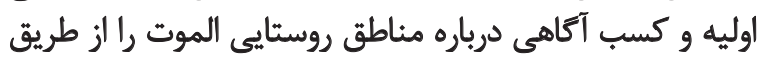

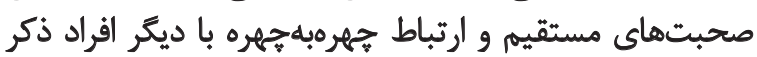

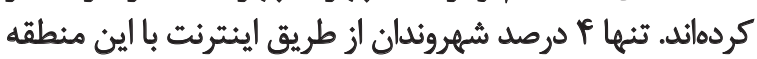

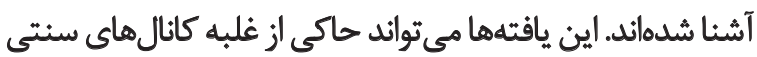

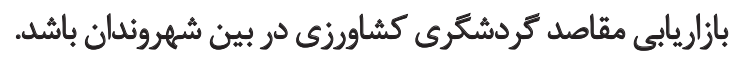
يافتههاى اين تحقيق نشان داد كه بهرهمندى از هواى باكيزه،

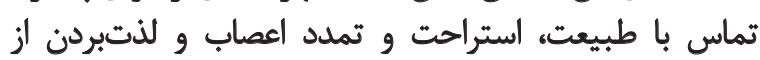

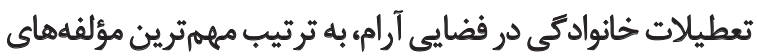

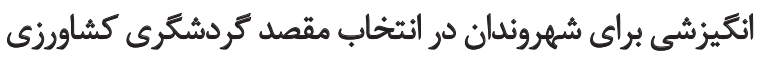

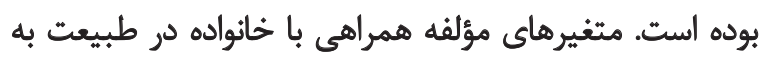

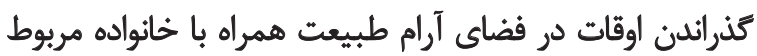

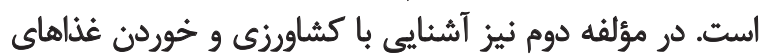
محلى و سالمتر از متغير هاى مهمه به شمار آمد.

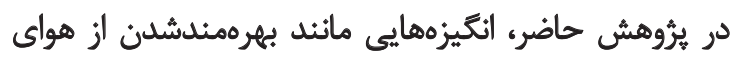

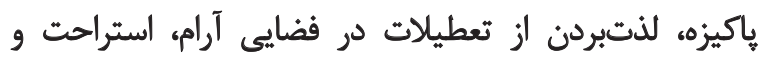

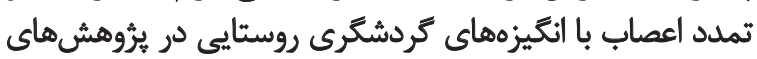

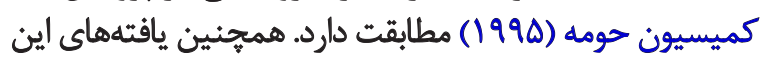

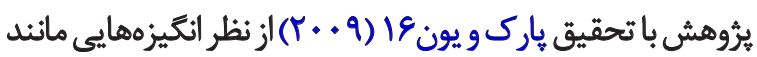

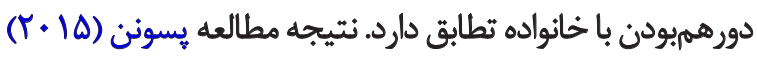

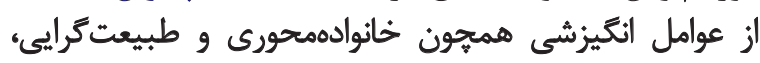

16. Park \& Yoon
بجرهمندشدن از هواي ياكيزه و ايجاد زميئه فعاليت براى تمام

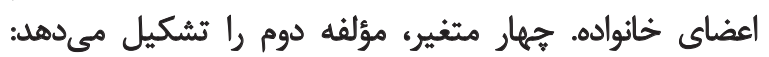

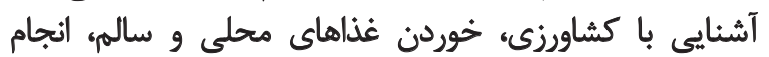

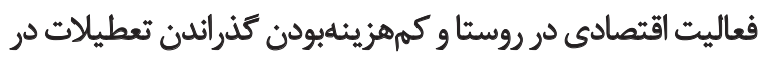

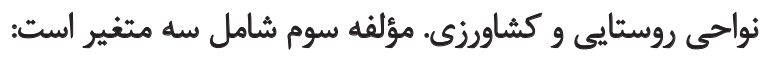

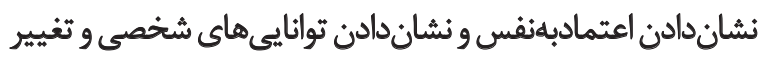

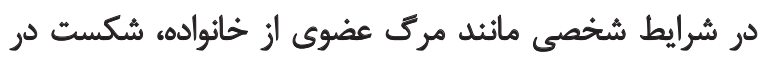

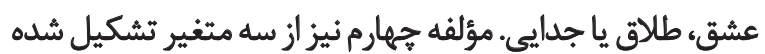

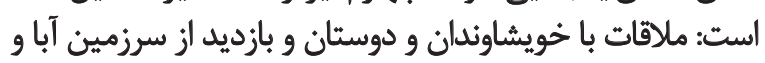

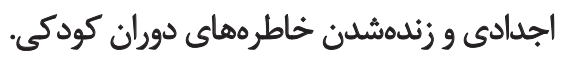

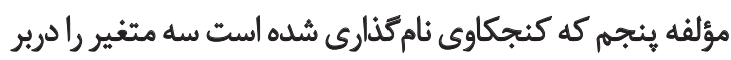

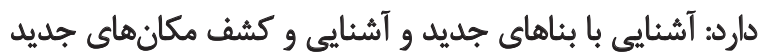

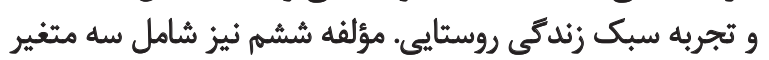

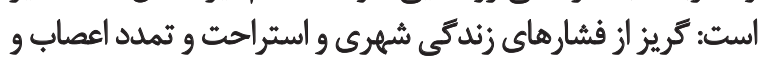

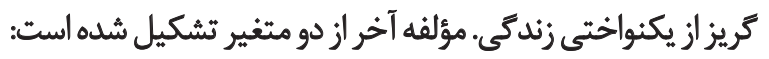

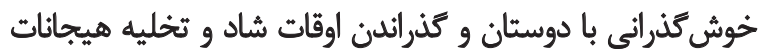

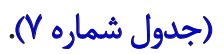

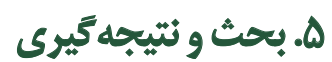

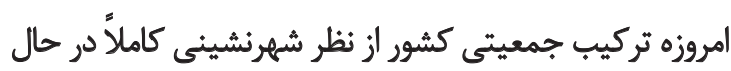

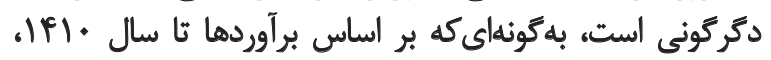

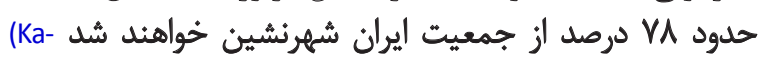

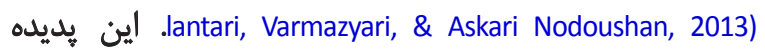

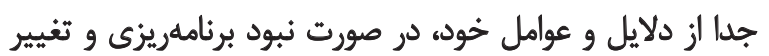

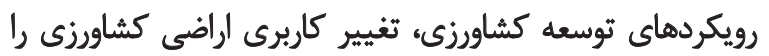

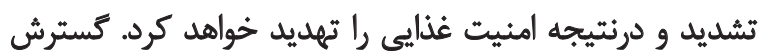

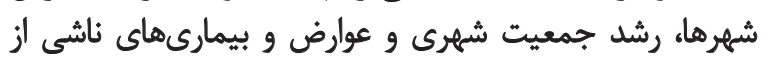

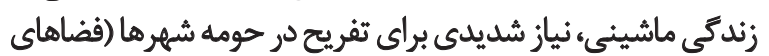

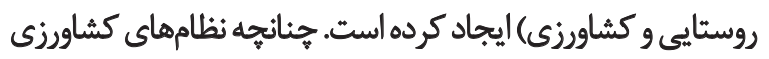

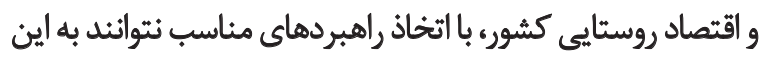

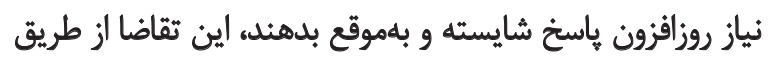

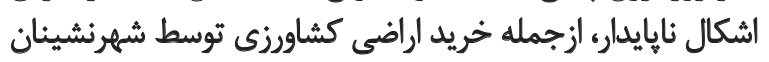

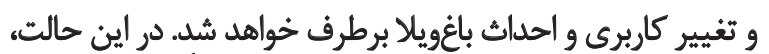

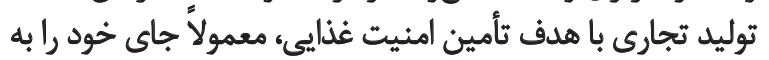

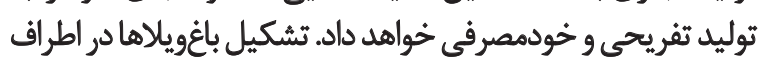
شهرهاى صنعتى و بزرى كشور نيز كواهى بر اين مدعاست.

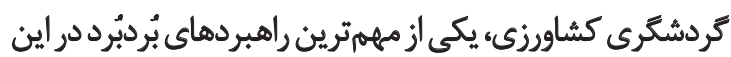

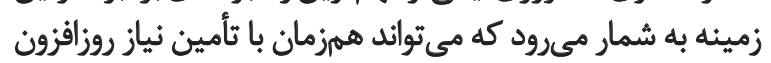

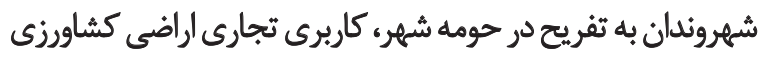

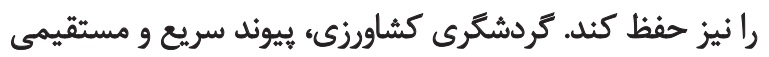

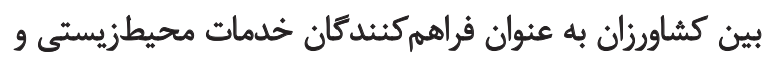

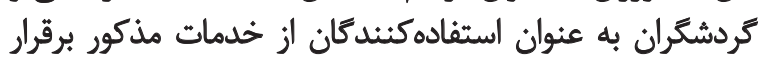

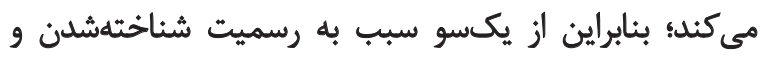




\section{References}

Aligholizadeh Firoozjai, N., Ramezanzadeh Lasboi, M., Asmaili, M. (2016). [Factors affecting the motivation of tourists in the tourist destination with an emphasis on desert rural areas and desert attractions (Persian)]. Geography Journal, 13(46), 301-321.

Artuger, S., \& Kendir, H. (2013). Agritourist motivations: The case of Turkey. International Journal of Business and Management, 8(21). doi: 10.5539/ijbm.v8n21p63

Busby, G., \& Rendle, S. (2000). The transition from tourism on farms to farm tourism. Tourism Management, 21(6), 635-642. doi: 10.1016/s0261-5177(00)00011-x.

Castan, O. J. M., Moreno, A., García, S., \& Crego, A. (2003). Psychosocial approach to tourism motivation: Variables involved in the choice of Madrid as a whole. Tourist Studies, 158, 5-41.

Cawley, M., Gillmor D. A., Leavy A., \& McDonagh P. (1995). Farm diversification: Studies relating to the West of Ireland. Dublin: Teagasc.

Countryside Commission. (1995). The environmental impact of leisure activities in the English countryside. Cheltenham: Countryside Commission.

Crompton, J. L. (1979). Motivations for pleasure vacation. Annals of Tourism Research, 6(4), 408-424. doi: 10.1016/0160-7383(79)90004-5

Dann, G. M. S. (1977). Anomie, ego-enhancement and tourism. Annals of Tourism Research, 4(4), 184-194. doi: 10.1016/01607383(77)90037-8

Dann, G. M. S. (1981). Tourist motivation an appraisal. Annals of Tourism Research, 8(2), 187-219. doi: 10.1016/0160-7383(81)90082-7

Devesa, M., Laguna, M., \& Palacios, A. (2010). The role of motivation in visitor satisfaction: Empirical evidence in rural tourism. Tourism Management, 31(4), 547-552. doi: 10.1016/j.tourman.2009.06.006.

Embacher, H. (1994). Marketing for Agri-tourism in Austria: Strategy and realisation in a highly developed tourist destination. Journal of Sustainable Tourism, 2(1-2), 61-76. doi: $10.1080 / 09669589409510684$

Evans, N. J., \& Ilbery, B. W. (1989). A conceptual framework for investigating farm-based accommodation and tourism in Britain. Journal of Rural Studies, 5(3), 257-266. doi: 10.1016/07430167(89)90004-1

Getz, D., \& Carlsen, J. (2000). Characteristics and goals of family and owner-operated businesses in the rural tourism and hospitality sectors. Tourism Management, 21(6), 547-560. doi: 10.1016/s02615177(00)00004-2

Goeldner, C. R., \& Ritchie, J. R. B. (2009). Tourism: Principles, practices, philosophies, New Jersey: Wiley.

Gorsuch, R. L. (1983). Factor analysis (2 ${ }^{\text {nd }}$ Ed.). Hillsdale, N. J.: Erlbaum.

Guadagnoli, E., \& Velicer, W. F. (1988). Relation to sample size to the stability of component patterns. Psychological Bulletin, 103(2), 265-275. doi: 10.1037/0033-2909.103.2.265

Hall, C. M., \& Jenkins, J. (1998). The policy dimension of rural tourism and recreation. In R. Butler, C. M. Hall, \& J. Jenkins (Eds.), Tourism and recreation in rural areas (pp. 19-42). Chichester: Wiley
آرامش جويب و ثمدد اعصاب و وريز از وضعيت موجود در ري

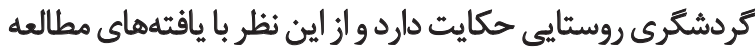
كنونى همراستا است.

البته بلهور كلي يافتتهاي اين مطالعه، ساختار عاملي متنوعترى

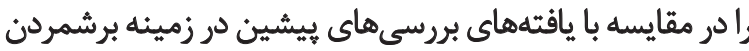

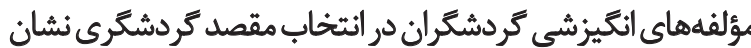

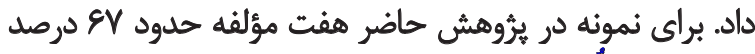

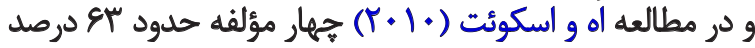

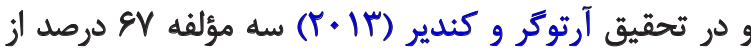

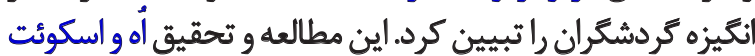

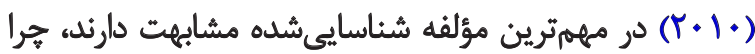

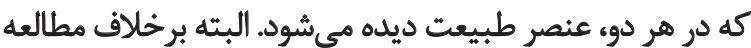

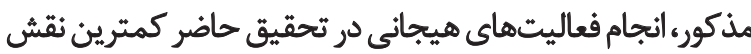

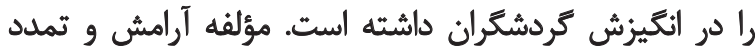

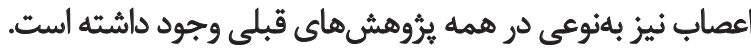

Lovering

بهطوركلى با توجه به يافتههاي تحقيق، راهكارهاى زير براي

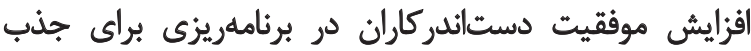

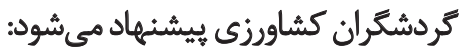

1. تمركز بيشتر بر خانوارهاى كمجمعيت و جوان توسط

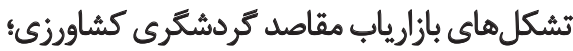

r. اطلاعرسانى و فرهنگسازى و اعتمادسازى بين شهروندان براى اقامت در منازل روستياييان:

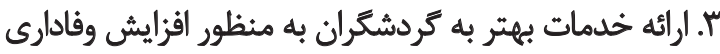

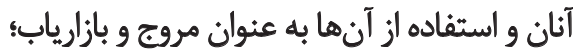

فأ. تأمين محيط مناسب براي كذراندن اوقات شهروندان در فضاي آرام طبيعت همراه با خانواده؛

ه. فراهمرسازى فضاها و امكانات مناسب با واحدهاى كشاورزى براي تثريح كودكان؛

$$
\text { 9. يخت و سرو غذاهاى محلى و سالم. }
$$

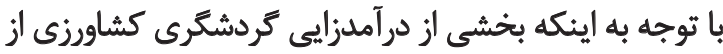

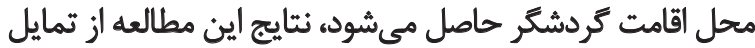

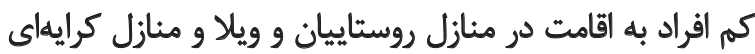

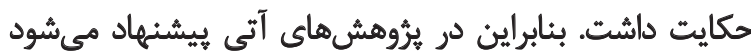

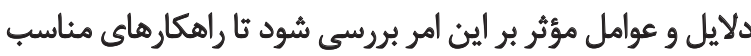

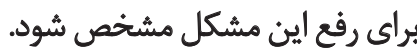
تشكر و قدردانى مقاله حامى مالى ندارد. 
Hjalager, A. M. (1996). Agricultural diversification into tourism. Tourism Management, 17(2), 103-111. doi: 10.1016/02615177(95)00113-1.

Kalantari, K. (2012). [Data processing and analysis in socio-economic research (Persian)]. Tehran: Sharif Publication.

Kalantari, K., Varmazyari, H., \& Askari Nodoushan, A. (2013). [The future perspective of rural population and challenges of sustainable development, management in Iran (Persian)]. Village and Development, 16(2), 1-23.

Kieselbach, S., \& Long, P. (1990). Tourism and the rural revitalization movement. Parks and Recreation, 25(3), 62-66.

Liu, A. (2006). Tourism in rural areas: Kedah, Malaysia. Tourism Management, 27(5), 878-889. doi: 10.1016/j.tourman.2005.05.007

Lobo, R. E., Goldman, G. E., Jolly, D. A., Wallace, B. D., Schrader, W. L., \& Parker, S. A. (1999). Agritourism benefits agriculture in San Diego County. California Agriculture, 53(6), 20-24. doi: 10.3733/ ca.v053n06p20.

Mansury, Y., \& Hara, T. (2007). Impact of organic food agritourism on a small rural economy: A social accounting matrix approach. SSRN Electronic Journal. doi: 10.2139/ssrn.954331.

Ministry of Agriculture of People's Republic of China. (2012). China agricultural development report. Beijing: China Agriculture Press.

Organisation for Economic Cooperation and Development (OECD). (1994). Tourism policy and international tourism in OECD countries 1991-1992. Paris: Organisation for Economic Cooperation and Development.

Council of Agriculture. (2014). COA annual report 2013 [Internet]. Retrieved from http:/ /eng.coa.gov.tw $/$ ws.php?id=2503670

Oh, J. Y., \& Schuett, M. A. (2010). Exploring expenditure-based segmentation for rural tourism: Overnight stay visitors versus excursionists to fee-fishing sites. Journal of travel $\mathcal{E}$ tourism marketing, 27(1), 31-50. doi: 10.1080/10548400903534824

Oppermann, M. (1997). Rural tourism in Germany-Farm and rural tourism operators. In S. Page, \& D. Getz (Eds.), The business of Rural Tourism: International Perspectives (pp. 108-119). London: International Thomson Business Press.

Park, D. B., \& Yoon, Y. S. (2009). Segmentation by motivation in rural tourism: A Korean case study. Tourism Management, 30(1), 99-108. doi: 10.1016/j.tourman.2008.03.011

Pesonen, J. A. (2015). Targeting rural tourists in the internet: comparing travel motivation and activity-based segments. Journal of Travel \& Tourism Marketing, 32(3), 211-226. doi: 10.1080/10548408.2014.895695

Pizam, A., \& Poleka, J. (1980). The vacation farm: A new form of tourism destination. In D. E. Hawkins, E. L. Shafer, \& J. M. Rovelstad (Eds.), Tourism Marketing and Management Issues (pp. 203216). Washington, D.C.: George Washington University.

Ranjbariyan, Z., Zaahedi, M. (2013). [Tourism marketing (Persian)]. Esfahan: Chahar Bagh Publication.

Southern Maryland Resource Conservation and Development Board. (2004). Taking the first step: Farm and ranch alternative enterprise and agritourism resource evaluation guide. Maryland: Southern Maryland Resource Conservation and Development.
Thompson, B. (2004). Exploratory and confirmatory factor analysis: Understanding concepts and applications. New York: American Psychological Association.

Uysal, M., \& Jurowski, C. (1994). Testing the push and pull factors. Annals of Tourism Research, 21(4), 844-846. doi: 10.1016/01607383(94)90091-4.

Weaver, D. B., \& Fennell, D. A. (1997). The vacation farm sector in Saskatchewan: A profile of operations. Tourism Management, 18(6), 357-365. doi: 10.1016/s0261-5177(97)00039-3

World Travel \& Tourism Council. (2014). Economic impact analysis. London: World Travel \& Tourism Council.

Tianyu, Y., \& Yongguang, Z. (2007). Community, governments and external capitals in China's rural cultural tourism: A comparative study of two adjacent villages. Tourism Management, 28, 96-107. doi: 10.1016/j.tourman.2005.12.025

Yoon, Y., \& Uysal, M. (2005). An examination of the effects of motivation and satisfaction on destination loyalty: A structural model. Tourism Management, 26(1), 45-56. doi: 10.1016/j.tourman.2003.08.016 